Review

\title{
Experimental modeling of hypothyroidism: principles, methods, several advanced research directions in cardiology
}

\author{
Aleksey M. Chaulin ${ }^{1,2}$, Julia V. Grigorieva ${ }^{1}$, Galina N. Suvorova ${ }^{1}$, Dmitry V. Duplyakov ${ }^{1,2}$ \\ ${ }^{1}$ Samara State Medical University, Samara, Russia \\ ${ }^{2}$ Samara Regional Clinical Cardiological Dispensary, Samara, Russia
}

Received 30 September 2020, Revised 25 February 2021, Accepted 20 April 2021

(C) 2020, Russian Open Medical Journal

\begin{abstract}
Hypothyroidism is one of the most common pathological conditions in modern clinical practice. Due to the fact that the targets of thyroid hormones are virtually all organs and tissues, the morphological and clinical manifestations arising with a deficiency of thyroid hormones are quite diverse. Experimental models of hypothyroidism in laboratory animals are widely used for preclinical study of the fundamental pathophysiological mechanisms underlying hypothyroidism, as well as for assessing the effectiveness of treatment-andprophylactic effects. Currently, several groups of effective models of hypothyroidism have been developed: dietary, surgical, medicamentous, genetic, radioactive and immunological. Each of the specified models is based on different principles, has advantages and disadvantages, and can be used depending on the goals and objectives of the experiment. In this review, we will consistently consider hypothyroidism modeling methods and indicate some promising areas of their use in cardiology.
\end{abstract}

Keywords: experimental models, hypothyroidism, dietary models, iodine, surgical models, thyroidectomy, medicamentous models, propylthiouracil, methimazole, genetic models, mutations, radioactive models, ${ }^{131} \mathrm{l}$, immunological model, methotrexate.

Cite as Chaulin AM, Grigorieva JV, Suvorova GN, Duplyakov DV. Experimental Modeling of Hypothyroidism: Principles, Methods, Several Advanced Research Directions in Cardiology. Russian Open Medical Journal 2021; 10: e0311.

Correspondence to Aleksey M. Chaulin. E-mail: alekseymichailovich22976@gmail.com.

\section{Introduction}

Hypothyroidism (underactive thyroid gland) is characterized by a thyroid hormone deficiency (thyroid hormones triiodothyronine, T3 and tetra-iodothyronine (thyroxine, T4)) and is one of the most common pathological conditions in the world. Insufficient production of thyroid hormones by the negative feedback mechanism activates thyrotropes of the adenohypophysis, forcing them to produce more thyroidstimulating hormone (TSH); therefore, the TSH concentration is regarded as one of the most significant diagnostic criteria for hypothyroidism. In some cases, the study of TSH level is used to diagnose subclinical hypothyroidism, where clinical manifestations are still absent and the thyroid hormones level is in the reference range [1-3]. Depending on the hypothalamic-pituitary-thyroid system (HPT) level when violation occurs, hypothyroidism is divided into primary (thyroid gland damage), secondary (pituitary gland damage, leading to a decrease in the TSH formation and, as a result, insufficient stimulation of thyroid follicular cells to the production of T3 and T4), as well as tertiary or central hypothyroidism (hypothalamus damage, leading to pituitary gland inhibition, where, in turn, the thyroid stimulation is inhibited). Depending on the time of occurrence, hypothyroidism is divided into congenital and acquired. Primary acquired hypothyroidism is most common and is caused by iodine deficiency in the human food, which is typical for endemic areas [3, 4]. But in those regions that are provided with a sufficient amount of iodine, the most common cause of primary acquired hypothyroidism is Hashimoto disease, an autoimmune disease that affects the thyroid parenchyma $[4,5]$. Other significant causes of primary thyroid hypofunction may be postoperative hypothyroidism $[3,4]$ and postradiation hypothyroidism [3,6]. Congenital hypothyroidism is most often caused by thyroid dysgenesis, hypoplasia, and a number of various mutations arising in enzymes responsible for the biosynthesis of thyroglobulin, thyroid hormones or their receptors $[4,7]$.

The clinical manifestations of hypothyroidism are very diverse, which is explained by the fact that the targets of thyroid hormones are virtually all organs and tissues of the mammalian body. The manifestation rate and morphological disorders arising in the structure of organs and tissues is determined by the degree of thyroid hormone deficiency. Most critically, hypothyroidism affects the nervous system [8], cardiovascular system (CVS) [9, 10], skin $[11,12]$, locomotor system [13] and sensory organs [3, 4, 14, 15]. Experimental models of hypothyroidism are widely used to study morphofunctional disorders in hypothyroidism and conduct preclinical assessment of the medical-preventive activities effectiveness. Despite the fact that hypothyroidism modeling methods were developed relatively long time ago, they are still relevant. As a result of the improvement of old and the development of new, more sensitive and specific laboratory, morphological and functional research methods, we received new data on pathological processes, the study of which will give a new look at old problems of diagnosis and treatment. 
The goal of this article was to review modern methods for hypothyroidism modeling in laboratory animals, to outline the advantages and disadvantages of certain experimental models of hypothyroidism, and to discuss some new promising research areas in cardiology. There are currently no reviews that fully cover the above aspects. Moreover, we can draw attention to the review by G. Argumedo et al. (2012) [16], which summarizes the principles of modeling congenital hypothyroidism. However, a lot of time has passed since that moment, and additional models of hypothyroidism were developed, in particular, several newly developed models by Russian researchers are disregarded. In addition, this article focuses on the principles of modeling congenital hypothyroidism and, in our opinion, the modern directions for research in cardiology remained insufficiently highlighted.

\section{On the principles of hypothyroidism modeling}

In general, the hypothyroidism modeling principles are based on the creation of the above-described conditions for hypothyroidism development in laboratory animals, namely, the use of food with a limited iodine content (dietary models) [17-19], removal of all or part of the thyroid gland (thyroidectomy) [12, 20], or thyroid blood supply disturbance due to ligation/coagulation of the superior and inferior thyroid arteries feeding it [21] (surgical models), administration of antithyroid (thyreostatic) drugs in the animal body [15, 22, 23] (medicamentous models), mammalian genome editing using molecular genetic methods (genetic models) [24-26], exposure of an animal body to a certain dose of a radioactive iodine (radioactive models) [27, 28], and administration of an immunosuppressive agent in an animal body (immunological model) [29]. These modeling principles allow to simulate almost all the basic conditions for hypothyroidism development necessary for the specific goals and objectives of the study.

Below we will sequentially and in more detail consider each of these models, view the main morphofunctional disorders that arise when using experimental models of hypothyroidism and outline their advantages and disadvantages.

Dietary model of hypothyroidism: Principles, advantages and disadvantages

lodine, despite its insignificant content in the mammalian body, is an essential microelement necessary for the generation of an adequate quantity of thyroid hormones. The daily norm of iodine for a person is on average 100-200 $\mu \mathrm{g}$, and iodine deficiency develops with an iodine level decrease to $40-80 \mu \mathrm{g}$. Although it does not lead to a clinically significant weakening of the thyroid function, but it is accompanied by impaired development of the central nervous system $[17,18]$. During pregnancy, the iodine clearance by kidneys increases, which requires an increase in the daily intake of iodine to $200 \mu \mathrm{g}$; otherwise, the delivery of iodine to the fetus decreases and a gradual formation of goiter occurs [30]. In addition, subclinical iodine deficiency adversely affects the cardiovascular system $[31,32]$. Considering the fact that an iodine deficiency in food is the most common cause of hypothyroidism $[17,18,30-32]$, the modeling of the last one is most closely matching the real clinical conditions due to the iodine-deficient diet. In experimental studies, the modeling of hypothyroidism by means of a dietary model was performed in pregnant rats. An iodine-deficient diet caused a decrease in the thyroid biosynthesis in both parental animals and their offspring, resulting to significant changes in the HPT system functioning by the negative feedback mechanism. In the young of the experimental group of animals, evident motor activity and cognitive functions disorders were observed during more than 2 months of observation [19]. The research team led by $\mathrm{M}$. Kulimbetov et al. developed an iodinedeficient diet based on the use of food products from iodineendemic regions of Uzbekistan. Hypothyroidism modeling using this diet was performed on white outbred rats. Researchers have shown that chronic iodine deficiency in food leads to the development of persistent hypothyroidism in rats, characterized by a decrease in T4 secretion by the thyroid follicular cells, as well as its structural rearrangement, namely, the formation of small follicular adenomas and increase in the thyroid weight [17]. With chronic iodine deficiency in the diet of pregnant rats, there is a violation of the nutrient transportation across the blood-brain barrier. The study showed that the offspring of females received an iodine-deficient diet for 8-12 weeks and the antithyroid potassium supplements thiocyanate ( $\mathrm{KSCN}, 25 \mathrm{mg} /$ day) gained weight more slowly compared to the control group. In addition, in the experimental group, there was a higher incidence of maternal death in labour and an increased likelihood of fetal death [33].

The advantages of the experimental dietary model of hypothyroidism are the gradual decrease in the iodine level in laboratory animals with no need for additional complex surgical and invasive manipulations, high similarity with real clinical conditions, and the disadvantages of the dietary model are the low availability and complexity of creating special commercial iodinedeficient diets, the need for accurate calculation the iodine content in food and the time required for the development of a hypothyroid state.

Surgical model of hypothyroidism: Principles, advantages and disadvantages

The main principle of surgical modeling of hypothyroidism, as a rule, is based on complete or partial removal of the thyroid gland in laboratory animals $[12,20]$. The result of thyroidectomy is a rapid and persistent deficiency of thyroid hormones. This model allows simulating the mechanisms of postoperative hypothyroidism development, which is very similar to real clinical situations. In experimental studies, the surgical model was used most often in comparison with other models. Rats, mice, rabbits, sheep, and other laboratory animals can be used as objects for surgical modeling of hypothyroidism. M. Tsujio et al. [12] simulated hypothyroidism in rats by complete thyroidectomy to study the skin morphology, including the epidermis and hair follicles. All rats of the experimental group, in 12 weeks post thyroidectomy, were noted with a slowdown in hair growth, dryness and pale skin, which is a very typical sign of hypothyroidism in humans. Histological examination of the epidermis revealed its sharp thinning, which is also characteristic of the hypothyroid state in humans [34]. However, despite the fact that hypothyroidism is the most common cause of alopecia in humans and animals, especially in dogs [35], hair growth in hypothyroid rats was inhibited, but without alopecia [12].

In another study, K. Chen et al. simulated hypothyroidism in sheep by removing the thyroid gland in order to study the state of the renin-angiotensin-aldosterone system (RAAS) [36, 37]. Against the background of thyroidectomy and decreased T3 and T4 level, the CVS functioning is disrupted: a heart rate and blood pressure 
fall, a decrease in cardiac output, relaxation of vascular smooth muscle cells, a decrease in peripheral vascular resistance and a response to an agonist of beta-adrenergic receptors (isoproterenol). These changes are associated with a decrease in the expression of the renin informational RNA and RAAS inhibition. Infusion of exogenous thyroxine restored both the T3 and T4 concentration and the expression level of the renin informational RNA and RAAS activity, which, in turn, led to the restoration of the above-described impaired functions of the CVS.

A. Kade and colleagues developed a new surgical model of hypothyroidism, where there is no need to perform thyroidectomy. The principle of this method is coagulation of the superior and inferior thyroid arteries, which leads to ischemia of this organ and its dysfunction [20].

The advantages of surgical models of hypothyroidism are in the ability to imitate the postoperative hypothyroidism observed in actual clinical conditions. Depending on the goals and objectives of the planned experiment, total and partial thyroidectomy, or unilateral or bilateral coagulation of the thyroid arteries can be performed to achieve the development of a certain severity of hypothyroidism. However, it should be noted that there are also several disadvantages of surgical models of hypothyroidism: a) the need for qualified surgical personnel when performing surgery; $b$ ) with partial removal of the thyroid gland, an immune response may develop against the remaining part of the thyroid gland, since it belongs to immune privileged organs; c) thyroidectomy also results in loss of parafollicular cells (C-cells) producing the hormone calcitonin, reducing the calcium level; d) due to anatomic features, surgical modeling of hypothyroidism often cause damage and parathyroidectomy, and this leads to a decrease in the hormone production that increases the blood calcium level (parathyroid hormone) and the development of hypoparathyroidism. The loss of cells producing calcium-regulatory peptides creates additional problems for a researcher: the need to monitor the blood calcium level, and in some cases, with a sharp decrease in concentration, it should be compensated to maintain the vital activity of the animal and eliminate interfering effects on the experimental results.

\section{Medicamentous model of hypothyroidism: Principles, advantages and disadvantages}

The principles of medicamentous modeling of the thyroid hypofunction consist in the administration of antithyroid (thyreostatic) agents to laboratory animals that disrupt the functioning of follicular cells and the production of thyroid hormones by the thyroid gland [15, 22, 23, 38-40]. This model is most often used in small animals such as rats and mice, since the consumption of drugs is insignificant and the study cost is much lower. It is possible to distinguish several varieties of medicamentous models of hypothyroidism, depending on the antithyroid agent and the method of its administration in the body of the experimental animal. Potassium thiocyanate, propylthiouracil mercazolil and its pharmacological analogues (thiamazole, methimazole, metisol, carbimazole) are widely used as thyreostatic agents for the thyroid hypofunction modeling.

In their experimental studies, Y. Kruk et al. [38] and E. Manuk et al. [39] simulated hypothyroidism in rats by introducing the thyrostatic agent mercazolil at a dose of $10 \mathrm{mg} / \mathrm{kg}$ for 8 weeks through a special gastric tube. The mechanism of methimazole is based on inhibition of the T4 and T3 production by blocking thyroid peroxidase (thyroperoxidase), which leads to a violation of the iodization of the amino acid tyrosine, i.e., inclusion of iodine in the composition of thyroid hormones.

R. Maksyutov et al. [40], to simulate hypothyroidism, administered mercazolil at a dose of $2.5 / 100 \mathrm{~g}$ BW into male rats with a body weight of $180-220 \mathrm{~g}$ through an intragastric tube during 3 weeks. At the end of the experiment, the histological examination of the thyroid gland showed following picture: decreased number of colloid in the follicles of the central cavity, and decreased distance from follicular thyrocytes; in some follicles, the colloid was completely absent, which is associated with a violation of the thyroid hormones synthesis; signs of thyrocytes destruction (decreased cells height and changed shape to oval, thyrocyte walls deformation and the folding, as well as chromatin induration). The data of the immunoenzymometric assay of free T4 confirmed the development of the hypothyroid state: the concentration of free T4 in the group of rats receiving mercazolil was $3.92 \pm 0.21 \mathrm{pmol} / \mathrm{l}$ versus $9.57 \pm 0.59 \mathrm{pmol} / \mathrm{l}$ in the control group of rats $(p<0.001)$ The study showed an incremental recovery of the thyroid functional activity in those hypothyroid animals that received iodine [40].

$\mathrm{N}$. Bhargava and colleagues modeled hypothyroidism by administering mercazolil in drinking water ( $0.05 \%$ solution) for 32 days. The development of hypothyroidism in experimental rats was evidenced by a significant decrease in temperature in the bowel lumen, systolic blood pressure, heart rate and serum concentration of triiodothyronine (total T3), thyroxine and T3 uptake in comparison with control rats that received water without mercazolil. In addition, the weight rate in rats treated with methimazole was significantly lower than in the control group of animals [41].

F. Kamilov et al. simulated hypothyroidism by intragastric administration of thiamazole at a dose of $2.5 \mathrm{mg}$ per $100 \mathrm{~g} \mathrm{BW}$ of a laboratory animal for 3 weeks. In addition to decreased thyroid hormones and increased TSH concentration, which is typical for hypothyroidism, these animals showed a significant decrease in the antioxidant enzymes activity (superoxide dismutase, glutathione peroxidase and catalase). When hypothyroid rats received iodine-containing biological active compounds, the functional activity of the pituitary-thyroid axis and activity of antioxidant enzymes were restored and, as a consequence, lipid peroxidation processes were inhibited [42].

In addition to mercazolil, propylthiouracil is often used to simulate hypothyroidism. Propylthiouracil reduces the concentration of thyroid hormones also by blocking thyroid peroxidase, which leads to a violation of the iodination of the amino acid tyrosine and the fusion of iodotyrosines during the T4 synthesis. This leads to the reproduction of some hypothyroidism manifestations, such as structural damage to the brain in the hippocampus and dentate gyrus. This damage results in cognitive impairments, changes in synaptic transmission, cognitive functions, learning and memory in rat offspring [43, 44].

The main advantages of medicamentous models of hypothyroidism are as follows: a) satisfactory reproducibility of clinical manifestations of hypothyroidism, typical for humans; b) a relatively simple model of hypothyroidism in its execution; c) antithyroid agents are widely available and are also highly soluble in water due to their hydrophilic properties; d) small consumption of drugs, provided that the experiment is carried out on small laboratory animals. Possible technical problems associated with 
errors in the calculation and dosage of drugs should be noted as disadvantages of medicamentous models of hypothyroidism. There is also some danger for experimenters, due to the fact that skin and tissues are permeable to these compounds.

Genetic model of hypothyroidism: Principles, advantages and disadvantages

In about $5 \%$ of cases, hypothyroidism develops as a result of mutations in genes encoding the TSH receptor or transcription factors - TITF1, FOXE1, or PAX8. E. Amendola et al. [45] developed a genetic model of hypothyroidism. It is about crossing of heterozygous mice with specific gene mutations in various transcription factors, such as TITF1 and PAX8, to obtain double heterozygotes. This demonstrated that the combination of two heterozygous null mutations for TITF1 and PAX8 leads to severe hypothyroidism characterized by elevated TSH concentration, decreased serum thyroid hormone levels, decreased body weight, thyroid hypoplasia, and an increased incidence of thyroid hemiagenesis [45]. The mechanisms underlying the hypothyroidism development in this model are associated with the fact that the transcription factors TITF1 and PAX8 play important roles in the organogenesis of the thyroid gland [46-50]. Both of these factors are necessary for the proper thyroid development in the first period of organogenesis $[46,47]$. In the second period, in an almost completely differentiated thyroid gland, TITF1 and PAX8 regulate the expression of genes responsible for the thyroid hormones biosynthesis such as the thyroglobulin ( $\mathrm{Tg})$ gene [48], the thyroid peroxidase (TPO) gene [49], and the $\mathrm{Na}+/ \mathrm{I}$ - symporter gene (NIS) [50].

K. Johnson and colleagues developed two genetic models of hypothyroidism in mice with mutations in the genes encoding double oxidase 2 (DUOX2) [24] and thyroperoxidase (TPO) [25]. The DUOX2 enzyme is needed for the hydrogen peroxide formation necessary for thyroperoxidase, due to which iodine is included in the thyroglobulin protein, which is one of the most important stages in the T4 and T3 biosynthesis. The researchers identified a thiamine-guanine-base point mutation $(T>G)$ in the exon 16 of DUOX2 gene, which led to the replacement of the amino acid valine with glycine in the 674 (V674G) position of the peptide chain of the protein molecule. Significant morphological and biochemical changes when using this model were: pituitary dysplasia, decreased thyroxine levels and increased TSH level. Moreover, in mice with DUOX2 gene mutation, body weight decreased by half as compared with control mice [24]. These manifestations, in general, corresponded to the manifestation of another mouse model of hypothyroidism with TPO gene mutation [51]. Other interesting morphological findings in DUOX2 mutant mice were changes in the cochlea, slowing the formation of the inner sulcus and spiral organ, and an abnormally thickened tectorial membrane. These changes were associated with hearing impairment in experimental animals [24].

M. Mustapha et al. studied a mouse model of secondary hypothyroidism - Snell dwarf mice with mutations in the pituitary transcription factor Pit1 (Pit ${ }^{\mathrm{dw}}$ ), which is involved in the development of adenohypophysis cells, including thyrotropes that produce TSH [52]. According to the development mechanism, this model corresponds to secondary hypothyroidism. Studying the morphological and pathophysiological changes in the auditory analyzer on a genetic model of hypothyroidism, the researchers found the following defects associated with hearing impairment: a) an irreversible decrease in the gene expression encoding the inwardly rectifying potassium channel (KCNJ10) in the vascular stria of Pit ${ }^{\mathrm{dw}}$ mice, which contributes to ion balance disorders and decrease in endocochlear potential; b) significant loss of outer hair cells in mice with the Pit ${ }^{\mathrm{dw}}$ mutation as a result of cell stress caused by lower gene expression encoding the voltage-gated potassium channel (KCNQ4); c) ultrastructural disorders of sensory cells and cells of the vascular stria. Thus, thyroid hormones are essential for the survival and normal functioning of snail cells. Based on the results obtained, it has been suggested that hypothyroidism and a decrease in hormone production with age are a risk factor for presbycusis (age-related hearing loss, ARHI) [52-54].

The advantage of genetic models of hypothyroidism is the ability to study specific mechanisms associated with the disruption of certain genes; good reproducibility of clinical signs of hypothyroidism typical for humans. At the same time, the difficulty of obtaining mutant animals, the need to use expensive equipment for such experimental studies should be considered the disadvantages of genetic models.

Radioactive model of hypothyroidism: Principles, advantages and disadvantages

The model principle consists in the administration of the radioactive isotope of iodine $\left({ }^{131} \mathrm{l}\right)$ to experimental animals. The optimal dose for hypothyroidism development in rats or mice is 150 microcuries $\left(\mu \mathrm{Ci}\right.$ ) of ${ }^{131} \mathrm{I}$. This dose corresponds to an absorbed dose of $0.5 \mathrm{~Gy}$, which is similar to the exposure level received by the population of the CIS countries when the environment was contaminated with radioactive iodine, which occurred during the accident at the Chernobyl NPP [27]. V. Usenko et al. modeled hypothyroidism by exposing maternal Wistar rats and their 168 newborns to ${ }^{131} \mathrm{I}$. Depending on the time of ${ }^{131} \mathrm{I}$, the experimental group of female animals was divided into 4 subgroups: 1) ${ }^{131}$ | exposure was carried out 12 days before mating, 2) on the 5th day of pregnancy, 3) on the 10th day of pregnancy, 4) on the 16th day of pregnancy. All experimental subgroups developed hypothyroidism characterized by a decrease in T4 levels by $43 \%$ and an increase in TSH level by around 8 times according to the negative feedback mechanism. However, the effect of maternal hypothyroidism on the fetal thyroid gland and nervous system development depended on the time of exposure to ${ }^{131} \mathrm{I}$. In general, in the body of newborn rats, there was a decrease in the brain and thyroid weight, as well as the body weight and hormonal status of newborns [27].

C. Reilly et al. simulated hypothyroidism using different doses of ${ }^{131}$ I: 50,150 or $450 \mu \mathrm{Ci}$. A dose of $50 \mu \mathrm{Ci}$ of ${ }^{131}$ I did not cause any changes in the thyroid hormonal status, while doses of 150 and $450 \mu \mathrm{Ci}$ caused a significant decrease in T4 level and an increase in TSH concentration, while T3 level remained unchanged [28]. V Torlak et al. studied morphofunctional changes in the thyroid gland of young rats under exposure to $64-277 \mu \mathrm{Ci}$ of ${ }^{131}$ I. The concentration of thyroid hormones and TSH was investigated before and three times after administration during a 6-month observation period. At the same time, it was noted that in animals of the experimental group (after a single exposure to ${ }^{131} \mathrm{l}$ ), the thyroxine level with age decreased significantly faster $(69.4 \pm 6.9 \mathrm{nM}$ to $25.4 \pm 3.2 \mathrm{nM})$ than in control animals $(64.8 \pm 8.16 \mathrm{nM}$ to $55.0 \pm 6.1 \mathrm{nM})$ The thyroid volume and mass in the experimental group was significantly lower than in the control. 
Histological examination of the thyroid gland of the experimental animals showed a hyaline thickening of the blood vessel wall and necrotic follicles. The severity of these changes did not depend on the ${ }^{131}$ I dose. Thus, the researchers concluded that hypothyroidism was prolonged after a single exposure to ${ }^{131} \mathrm{I}$, regardless of dose [55].

Considering that parafollicular cells (C-cells), which play an important role in calcium homeostasis, are located near the thyroid follicular cells, exposure to ${ }^{131}$ I can significantly damage these cells and cause calcitonin deficiency [56]. According to the experimental results, after exposure to ${ }^{131} \mathrm{I}$, the number of parafollicular cells in newborns decreases [57], and restoration of its number does not occur even 40 days after application of ${ }^{131}$, [58]. This effect on C-cells creates the need for additional monitoring of a blood calcium level using a radioactive model. J. Hershman et al. also showed that exposure to ${ }^{131}$ I causes doublestrand breaks in the DNA of thyroid cells, which is a predisposing factor for neoplasia development [59]. The incidence rate of papillary thyroid cancer may be associated with the initiation of DNA double-strand breaks that occur when exposed to carcinogenic compounds [59]. Thus, the experimental model developed by J. Hershman et al. can be used to assess the effectiveness of thyroid cancer treatment.

The advantages of the radioactive model of hypothyroidism are the persistent and long-term development of hypothyroidism even with the use of a small dose of radioactive iodine, which is necessary for the development of destruction and/or dysfunction of hormone-producing thyroid cells. The disadvantages of the radioactive model lie in the fact that it requires specialized skills in handling radioactive isotopes and the increased risk of adverse effects on researchers. Also, the use this model showed a significant effect on the thyroid parafollicular cells. Thus, there is a need for additional monitoring of the blood calcium level.

Immunological model of hypothyroidism: Principles, advantages and disadvantages

The endocrine and immune systems are in close interaction, significantly relating to each other. It has been found that the thyroid functioning depends on the immune status of the mammalian organism. The literature describes the case of hypothyroidism after the use of a cytostatic drug from the group of antimetabolites and a folic acid antagonist - methotrexate [60]. S. Kashchenko and his colleague in an experimental study surveyed the effect of methotrexate on the structural and functional state of the thyroid gland. The researchers have shown that administration of methotrexate at a dose of $50 \mu \mathrm{g}$ to young male rats leads to significant morphological changes in the thyroid gland on the 7th day of observation: deformation of the thyroid follicles, change in the normal (cubic) shape of follicular thyrocytes to abnormal (low-prismatic and flattened), in some areas, thyrocytes damage and cell debris formation due to which the boundaries between adjacent follicles became indistinct. As for the colloid inside the follicles, it became lumpy, layered and unevenly distributed. The thyroid weight of the experimental group decreased by about $10 \%$ on the 7th day in comparison with the control group of animals. With the introduction of an immunomodulator (Imunofan), the morphofunctional parameters of the thyroid gland were restored [29]. Thus, an immunological model of hypothyroidism may be of interest for studying and improving therapeutic and prophylactic strategies when using cytostatic drugs toxic to the thyroid gland.

Summarizing all of the above, we can distinguish the following principles and methods of hypothyroidism experimental modeling in laboratory animals (Table 1), which would allow studying necessary morphofunctional aspects of hypothyroidism and conducting a preclinical efficacy assessment of the treatment and prophylaxis.

Some promising research directions using experimental models in cardiology

The use of experimental models of hypothyroidism in cardiology is of considerable interest, since often patients suffering from cardiovascular diseases (CVD) have comorbid pathologies, in particular, concomitant thyroid diseases, which requires special diagnostic and treatment approaches. Determination of thyroid hormones in the blood serum of patients with CVD is not included in the diagnostic standards, and therefore, in most patients with CVD, subclinical hypothyroidism remains underdiagnosed [31, 32].

The discovery of new regulatory biomolecules that significantly affect the pathogenesis of CVD also requires additional experimental studies using animal models to study their interrelation with thyroid hormones. As an example, we present the currently actively studied molecules of microribonucleic acids (microRNAs) [61] and proprotein convertase subtilisin/kexin type 9 (PCSK9) $[62,63]$. In his recent study, Y. Gong et al. found that patients with subclinical hypothyroidism (elevated TSH level) have significantly higher PCSK9 levels compared to healthy patients (151.29 (89.51-293.03) vs. 84.70 (34.98-141.72) ng/ml, p <0.001). These data indicate that TSH increases the expression of PCSK9 in the liver [64]. Given that higher levels of PCSK9 are risk factors for the development of atherosclerosis and cardiovascular diseases $[62,63]$, subclinical hypothyroidism can also be considered as a risk factor for these conditions. Therefore, additional studies are needed using experimental models to study these pathophysiological relationships.

Table 1. Underlying principles and methods of hypothyroidism modeling according to [16] (amended and supplemented) Hypothyroidism models Modeling principles

Surgical models
Dietary model


As for the relationship between hypothyroidism and some microRNA molecules, it was shown that the expression of miRNA regulated by thyroid hormones can suppress the development of pathological myocardial hypertrophy [65-67]. Research of these mechanisms through experimental and clinical studies represents considerable interest in terms of improving diagnostic and treatment strategies for management of patients with CVD and hypothyroidism.

In addition, due to the improvement of laboratory methods for cardiac troponins determination, it has been suggested that highsensitive troponins [68] are associated with the thyroid hormones level $[69,70]$. Interestingly that the circadian rhythms of thyroid hormones coincide with the circadian rhythms of cardiac troponins $[69,70]$. It is very likely that thyroid hormones are one of the triggers for the release of cytoplasmic fraction of troponins from cardiomyocytes [71]. These observations can be of both fundamental and practical importance in extending the diagnostic value of these biomarkers.

\section{Conclusion}

Hypothyroidism is one of the most common pathological conditions and its manifestations are diverse. Currently, experimenters have a lot of useful experimental models (dietary, surgical, medicamentous, genetic, radioactive, immunological) for studying the clinical and morphological manifestations of thyroid hypofunction. Experimental models of hypothyroidism are a valuable research tool for studying both the fundamental mechanisms underlying the pathogenesis of organ and tissue damage in hypothyroidism and for potential practical use, including the development and preclinical evaluation of new drugs effectiveness. These studies on experimental models are relevant and promising for endocrinologists, and also for doctors of other specialties, as they can improve preventive measures and reasonably carry out therapeutic interventions. One of the promising trends for the use of hypothyroidism experimental models in cardiology is the study of the thyroids interrelation with recently discovered regulatory molecules and biomarkers, in particular, microRNA, PCSK9, and high-sensitive cardiac troponins.

\section{Conflict of interest}

Authors declare no conflicts of interest.

\section{Funding}

This study did not have an external funding.

\section{References}

1. Chaker L, Bianco AC, Jonklaas J, Peeters RP. Hypothyroidism. Lancet 2017; 390(10101): 1550-1562. https://doi.org/10.1016/S01406736(17)30703-1.

2. Chiovato L, Magri F, Carlé A. Hypothyroidism in Context: Where We've Been and Where We're Going. Adv Ther 2019; 36(Suppl 2): 47-58. https://doi.org/10.1007/s12325-019-01080-8.

3. Skvortsov VV, Tumarenko AV. Klinicheskaya endokrinologiya. Kratkiy kurs. St. Petersburg, Russia: SpecLit. 2016; 186 p. Russian. https://e.lanbook.com/book/103961.

4. Dedov II, Mel'nichenko GA, Fadeyev VF. Endokrinologiya. Mosow, Russia: GEOTAR-Media. 2013; 432p. Russian.

5. Rozhko VA. Current state of the autoimmune thyroiditis problem. Health and Ecology Issues 2019; (2(60)): 4-13. Russian. https://elibrary.ru/item.asp?id=38548113.
6. Tsyb AF, Matveenko EG, Nestaiko GB, Gorobets VF. Radiation associated hypothyroidism (Scientific review). Radiaciya i risk 1997; 10: 61-83. Russian

7. Vitebskaya AV, Igamberdieva TV. Congenital hypothyroidism in pediatric practice. Medical Council 2016; (7): 94-110. Russian. https://doi.org/10.21518/2079-701x-2016-07-94-100.

8. Rashidy-Pour A, Derafshpour L, Vafaei AA, Bandegi AR, Kashefi A Sameni HR, et al. Effects of treadmill exercise and sex hormones on learning, memory and hippocampal brain-derived neurotrophic factor levels in transient congenital hypothyroid rats. Behav Pharmacol 2020 31(7): 641-651. https://doi.org/10.1097/FBP.0000000000000572.

9. Deng H, Zhou S, Wang X, Qiu X, Wen Q, Liu S, et al. Cardiovascular risk factors in children and adolescents with subclinical hypothyroidism: $A$ protocol for meta-analysis and systematic review. Medicine (Baltimore) 2020; 99(31): e20462. https://doi.org/10.1097/MD.0000000000020462.

10. Chuhray SM, Lavrynenko VE, Kaminsky RF, Dzevulska IV, Malikov OV, Kovalchuk OI, et al. Morphofunctional status of cardio-vascular system of rats with congenital hypothyreosis. Wiad Lek 2019; 72(2): 229-233. https://pubmed.ncbi.nlm.nih.gov/30903778.

11. Kachuk YuV. Skin lesions under thyroid dysfunction. Dermatology. Cosmetology. Sexopathology 2013; 1-4: 228-232. Russian. http://repo.dma.dp.ua/2780/

12. Tsujio M, Yoshioka K, Satoh M, Watahiki Y, Mutoh K. Skin morphology of thyroidectomized rats. Vet Pathol 2008; 45(4): 505-511. https://doi.org/10.1354/vp.45-4-505.

13. Boryushkina V, Ahmed S, Quadri K, Ramdass A. Recurrent Rhabdomyolysis Induced by Severe Hypothyroidism. Cureus 2019; 11(6): e4818. https://doi.org/10.7759/cureus.4818.

14. Sharlin DS, Ng L, Verrey F, Visser TJ, Liu Y, Olszewski RT, et al. Deafness and loss of cochlear hair cells in the absence of thyroid hormone transporters Slc16a2 (Mct8) and Slc16a10 (Mct10). Sci Rep 2018; 8(1): 4403. https://doi.org/10.1038/s41598-018-22553-w.

15. Berkowitz BA, Luan $\mathrm{H}$, Roberts RL. Effect of methylimidazole-induced hypothyroidism in a model of low retinal neovascular incidence. Invest Ophthalmol Vis Sci 2004; 45(3): 919-921. https://doi.org/10.1167/iovs.03-0914.

16. Argumedo GS, Sanz CR, Olguín HJ. Experimental models of developmental hypothyroidism. Horm Metab Res 2012; 44(2): 79-85. https://doi.org/10.1055/s-0031-1297941.

17. Kulimbetov MT, Rashitov MM, Saatov TS. Modeling experimental hypothyroidism due to natural chronic iodine deficiency in the diet. International journal of endocrinology 2009; (2(20)). Russian. http://www.mif-ua.com/archive/article/8754

18. Delange $F$, Lecomte $P$. lodine supplementation: benefits outweigh risks. Drug Saf 2000; 22(2): 89-95. https://doi.org/10.2165/00002018200022020-00001.

19. van Wijk N, Rijntjes $E$, van de Heijning BJ. Perinatal and chronic hypothyroidism impair behavioural development in male and female rats. Exp Physiol 2008; 93(11): 1199-1209. https://doi.org/10.1113/expphysiol.2008.042416.

20. Helal MB, Labah DA, El-Magd MA, Sarhan NH, Nagy NB. Thyroidectomy induces thyroglobulin formation by parotid salivary glands in rats. Acta Histochem 2020; 122(5): 151568 https://doi.org/10.1016/j.acthis.2020.151568.

21. Kade AK, Smeyanova LA, Liyeva KA, Zanin SA, Trofimenko Al, Dzhidzhikhiya KM. Gipotireoid modeling of the condition at the rat by means of coagulation of the top and bottom thyroid artery on the right. Fundamental research 2013; (12-1): 116-121. Russian. https://elibrary.ru/item.asp?id=20960834.

22. Hasebe M, Matsumoto I, Imagawa T, Uehara M. Effects of an antithyroid drug, methimazole, administration to rat dams on the cerebellar cortex development in their pups. Int J Dev Neurosci 2008; 26(5): 409-414. https://doi.org/10.1016/j.ijdevneu.2008.03.007. 
23. Kamilov FK, Ganeyev TI, Kozlov VN, Kuznetsova EV, Maksyutov RR. The choice of a method of application and dosage of thiamazole for modeling hypothyroidism in laboratory rats. Journal Biomed 2018; (1): 59-70. Russian. https://elibrary.ru/item.asp?id=32763917.

24. Johnson KR, Marden CC, Ward-Bailey P, Gagnon LH, Bronson RT, Donahue LR. Congenital hypothyroidism, dwarfism, and hearing impairment caused by a missense mutation in the mouse dual oxidase 2 gene, Duox2. Mol Endocrinol 2007; 21(7): 1593-1602. https://doi.org/10.1210/me.2007-0085.

25. Johnson KR, Gagnon LH, Longo-Guess CM, Harris BS, Chang B. Hearing impairment in hypothyroid dwarf mice caused by mutations of the thyroid peroxidase gene. J Assoc Res Otolaryngol 2014; 15(1): 45-55. https://doi.org/10.1007/s10162-013-0427-7.

26. Löf C, Patyra K, Kero A, Kero J. Genetically modified mouse models to investigate thyroid development, function and growth. Best Pract Res Clin Endocrinol Metab 2018; 32(3): 241-256. https://doi.org/10.1016/i.beem.2018.03.007.

27. Usenko V, Lepekhin E, Lyzogubov V, Kornilovska I, Ushakova G, Witt M. The influence of low doses 1311-induced maternal hypothyroidism on the development of rat embryos. Exp Toxicol Pathol 1999; 51(3): $223-$ 227. https://doi.org/10.1016/S0940-2993(99)80100-6.

28. Reilly CP, Symons RG, Wellby ML. A rat model of the 1311-induced changes in thyroid function. J Endocrinol Invest 1986; 9(5): 367-370. https://doi.org/10.1007/bf03346944.

29. Kashchenko SA, Mosin DV. Structural and organometric changes in rat thyroid gland under early immunosuppressive and immunomodulatory therapy. Ulyanovsk Medico-Biological Journal 2019; (1): 110-118. Russian. https://doi.org/10.34014/2227-1848-2019-1-110-118.

30. Dragun IE, Dubrovina NV, Tverdikova MA. Prevention of iodine deficiency diseases in pregnant women. Russian Medical Journal. Mother and Child. 2010; 18(4): 192-195. Russian. https://elibrary.ru/item.asp?id=18105222.

31. Delitala AP, Scuteri A, Maioli M, Mangatia P, Vilardi L, Erre GL. Subclinical hypothyroidism and cardiovascular risk factors. Minerva Med 2019; 110(6): 530-545. https://doi.org/10.23736/S00264806.19.06292-X.

32. Gong N, Gao C, Chen X, Fang Y, Tian L. Endothelial Function in Patients with Subclinical Hypothyroidism: A Meta-Analysis. Horm Metab Res 2019; 51(11): 691-702. https://doi.org/10.1055/a-1018-9564.

33. Sundari SB, Venu L, Sunita $Y$, Raghunath M. Chronic maternal dietary iodine deficiency but not thiocyanate feeding affects maternal reproduction and postnatal performance of the rat. Indian J Exp Biol 2007; 45(7): 603-609. https://pubmed.ncbi.nlm.nih.gov/17821855.

34. Holt PJ, Marks R. The epidermal response to change in thyroid status. $J$ Invest Dermatol 1977; 68(5): 299-301. https://doi.org/10.1111/15231747.ep12494564.

35. Panciera DL. Hypothyroidism in dogs: 66 cases (1987-1992). J Am Vet Med Assoc 1994; 204(5): 761-767. https://pubmed.ncbi.nlm.nih.gov/8175472.

36. Chen K, Carey LC, Valego NK, Liu J, Rose JC. Thyroid hormone modulates renin and ANG II receptor expression in fetal sheep. Am J Physiol Regul Integr Comp Physiol 2005; 289(4): R1006-R1014. https://doi.org/10.1152/ajpregu.00046.2005.

37. Chen K, Carey LC, Valego NK, Rose JC. Thyroid hormone replacement normalizes renal renin and angiotensin receptor expression in thyroidectomized fetal sheep. Am J Physiol Regul Integr Comp Physiol 2007; 293(2): R701-R706. https://doi.org/10.1152/ajpregu.00232.2007.

38. Kruk YY, Mahneva AV, Zolotuhin SY, Bitukov DS. Features of manifestation of oxidative stress in hypothyreosis of different severity degrees in the experiment. Pathologia 2011; 8(2): 62-65. Russian. https://www.elibrary.ru/item.asp?id=20868729.

39. Manuk ES, Izatulin VG, Vasilieva LS. The correction of the experimental hypothyrosis with plant preparation of aconitum baikalense bayacon.
Siberian Medical Journal (Irkutsk) 2008; 76(1): 82-84. Russian. https://www.elibrary.ru/item.asp?id=17844860.

40. Maksyutov RR, Baimatov VN, Ponomareva LF, Kozlov VN. Study of thyroid status in rats while correcting disorders induced by experimental hypothyroidism. Russian Veterinary Journal. Productive $\begin{array}{llll}\text { Animals } & \text { 2013; } & \text { (3): } & \end{array}$ https://www.elibrary.ru/item.asp?id=20185068.

41. Bhargava HN, Ramarao P, Gulati A, Matwyshyn GA, Prasad R. Brain and pituitary receptors for thyrotropin-releasing hormone in hypothyroid rats. Pharmacology 1989; 38(4): 243-252. https://doi.org/10.1159/000138543.

42. Kamilov FKh, Mamtsev AN, Kozlov VN, Abdullina GM, Lobyreva OV. Activity of antioxidant enzymes and processes of free radical oxidation in experimental hypothyroidism and correction of thyroid shifts with iodized polysaccharide complexes. Kazan Medical Journal 2012; 93(1): 116-119. Russian. https://www.elibrary.ru/item.asp?id=17650723.

43. Kawada J, Mino H, Nishida M, Yoshimura Y. An appropriate model for congenital hypothyroidism in the rat induced by neonatal treatment with propylthiouracil and surgical thyroidectomy: studies on learning ability and biochemical parameters. Neuroendocrinology 1988; 47(5): 424-430. https://doi.org/10.1159/000124945.

44. Gilbert ME. Alterations in synaptic transmission and plasticity in area CA1 of adult hippocampus following developmental hypothyroidism. Brain Res Dev Brain Res 2004; 148(1): 11-18. https://doi.org/10.1016/j.devbrainres.2003.09.018.

45. Amendola E, De Luca P, Macchia PE, Terracciano D, Rosica A, Chiappetta $G$, et al. A mouse model demonstrates a multigenic origin of congenital hypothyroidism. Endocrinology 2005; 146(12): 5038 5047. https://doi.org/10.1210/en.2005-0882.

46. Kimura S, Hara Y, Pineau T, Fernandez-Salguero P, Fox $\mathrm{CH}$, Ward JM, et al. The T/ebp null mouse: thyroid-specific enhancer-binding protein is essential for the organogenesis of the thyroid, lung, ventral forebrain, and pituitary. Genes Dev 1996; 10(1): 60-69. https://doi.org/10.1101/gad.10.1.60.

47. Parlato R, Rosica A, Rodriguez-Mallon A, Affuso A, Postiglione MP, Arra $C$, et al. An integrated regulatory network controlling survival and migration in thyroid organogenesis. Dev Biol 2004; 276(2): 464-475. https://doi.org/10.1016/j.ydbio.2004.08.048

48. De Felice M, Damante G, Zannini M, Francis-Lang H, Di Lauro R. Redundant domains contribute to the transcriptional activity of the thyroid transcription factor 1. J Biol Chem 1995; 270(44): 26649-26656. https://doi.org/10.1074/jbc.270.44.26649.

49. Zannini M, Francis-Lang $H$, Plachov D, Di Lauro R. Pax-8, a paired domain-containing protein, binds to a sequence overlapping the recognition site of a homeodomain and activates transcription from two thyroid-specific promoters. Mol Cell Biol 1992; 12(9): 4230-4241. https://doi.org/10.1128/mcb.12.9.4230.

50. Ohno M, Zannini M, Levy O, Carrasco N, Di Lauro R. The paired-domain transcription factor Pax8 binds to the upstream enhancer of the rat sodium/iodide symporter gene and participates in both thyroidspecific and cyclic-AMP-dependent transcription. Mol Cell Biol 1999; 19(3): 2051-2060. https://doi.org/10.1128/mcb.19.3.2051.

51. Takabayashi S, Umeki K, Yamamoto E, Suzuki T, Okayama A, Katoh H. A novel hypothyroid dwarfism due to the missense mutation Arg479Cys of the thyroid peroxidase gene in the mouse. Mol Endocrinol 2006; 20(10): 2584-2590. https://doi.org/10.1210/me.2006-0099.

52. Mustapha M, Fang Q, Gong TW, Dolan DF, Raphael Y, Camper SA, et al. Deafness and permanently reduced potassium channel gene expression and function in hypothyroid Pit1dw mutants. I Neurosci 2009; 29(4): 1212-1223. https://doi.org/10.1523/JNEUROSCI.495708.2009.

53. Fransen E, Lemkens N, Van Laer L, Van Camp G. Age-related hearing impairment (ARHI): environmental risk factors and genetic prospects. Exp Gerontol 2003; 38(4): 353-359. https://doi.org/10.1016/s05315565(03)00032-9. 
54. Van Eyken E, Van Laer L, Fransen E, Topsakal V, Lemkens N, Laureys W, et al. KCNQ4: a gene for age-related hearing impairment? Hum Mutat 2006; 27(10): 1007-1016. https://doi.org/10.1002/humu.20375.

55. Torlak V, Zemunik T, Modun D, Capkun V, Pesutić-Pisać V, Markotić A, et al. 131 I-induced changes in rat thyroid gland function. Braz J Med Biol Res 2007; 40(8): 1087-1094. https://doi.org/10.1590/S0100879X2006005000127.

56. Bayraktar M, Gedik O, Akalin S, Usman A, Adalar N, Telatar F. The effect of radioactive iodine treatment on thyroid $\mathrm{C}$ cells. Clin Endocrinol (Oxf) 1990; 33(5): 625-630. https://doi.org/10.1111/i.13652265.1990.tb03901.x.

57. Thurston V, Williams ED. The effect of radiation on thyroid C cells. Acta $\begin{array}{llll}\text { Endocrinol } & \text { (Copenh) } & \text { 1982; } & \end{array}$ https://doi.org/10.1530/acta.0.0990072.

58. Feinstein RE, Gimeno EJ, el-Salhy M, Wilander E, Walinder G. Evidence of C-cell destruction in the thyroid gland of mice exposed to high 1311 doses. Acta Radiol Oncol 1986; 25(3): 199-202. https://doi.org/10.3109/02841868609136405.

59. Hershman JM, Okunyan A, Rivina Y, Cannon S, Hogen V. Prevention of DNA double-strand breaks induced by radioiodide-(131)I in FRTL-5 thyroid cells. Endocrinology 2011; 152(3): 1130-1135. https://doi.org/10.1210/en.2010-1163.

60. Chaddha U, English R, Daniels J, Walia R, Mehta AC, Panchabhai TS. A 58-Year-Old Man With Fatigue, Weight Loss, and Diffuse Miliary Pulmonary Opacities. Chest 2017; 151(6): e131-e134. https://doi.org/10.1016/i.chest.2016.11.015.

61. Chaulin AM, Duplyakov DV. MicroRNAs in Atrial Fibrillation: Pathophysiological Aspects and Potential Biomarkers. International Journal of Biomedicine 2020; 10(3): 198-205. https://doi.org/10.21103/article10(3) ra3.

62. Chaulin AM, Duplyakov DV. PCSK-9: modern views about biological role and possibilities of use as a diagnostic marker for cardiovascular diseases. Part 1. Cardiology: News, Opinions, Training 2019; 7(2): 4557. Russian. https://doi.org/10.24411/2309-1908-2019-12005.

63. Chaulin AM, Duplyakov DV. PCSK-9: modern views about biological role and possibilities of use as a diagnostic marker for cardiovascular diseases. Part 2. Cardiology: News, Opinions, Training 2019; 7(4): 2435. Russian. https://doi.org/10.24411/2309-1908-2019-14004.

64. Gong Y, Ma Y, Ye Z, Fu Z, Yang P, Gao B, et al. Thyroid stimulating hormone exhibits the impact on LDLR/LDL-c via up-regulating hepatic PCSK9 expression. Metabolism 2017; 76: 32-41. https://doi.org/10.1016/j.metabol.2017.07.006.

65. Forini F, Nicolini G, Pitto L, lervasi G. Novel Insight Into the Epigenetic and Post-transcriptional Control of Cardiac Gene Expression by Thyroid Hormone. Front Endocrinol (Lausanne) 2019; 10: 601. https://doi.org/10.3389/fendo.2019.00601.

66. Janssen R, Zuidwijk MJ, Kuster DW, Muller A, Simonides WS. Thyroid Hormone-Regulated Cardiac microRNAs are Predicted to Suppress Pathological Hypertrophic Signaling. Front Endocrinol (Lausanne) 2014; 5: 171. https://doi.org/10.3389/fendo.2014.00171.

67. Diniz GP, Lino CA, Moreno CR, Senger N, Barreto-Chaves MLM. MicroRNA-1 overexpression blunts cardiomyocyte hypertrophy elicited by thyroid hormone. J Cell Physiol 2017; 232(12): 3360-3368. https://doi.org/10.1002/jcp.25781.

68. Chaulin AM, Karslyan LS, Grigoriyeva EV, Nurbaltaeva DA, Duplyakov DV. Clinical and Diagnostic Value of Cardiac Markers in Human Biological Fluids. Kardiologiia 2019; 59(11): 66-75. Russian. https://doi.org/10.18087/cardio.2019.11.n414.

69. Klinkenberg $L$, Wildi $K$, van der Linden $N$, Kouw IW, Niens $M$, Twerenbold $\mathrm{R}$, et al. Diurnal Rhythm of Cardiac Troponin: Consequences for the Diagnosis of Acute Myocardial Infarction. Clin Chem 2016; 62(12): 1602-1611. https://doi.org/10.1373/clinchem.2016.257485.

70. Tsareva YuO, Mayskova EA, Fedotov EA, Shvarts YG. Circadian rhythms of thyroid hormones in patients with ischemic heart disease, arterial hypertension, and atrial fibrillation. Kardiologiia 2019; 59(3S): 23-29. Russian. https://doi.org/10.18087/cardio.2506

71. Chaulin AM, Duplyakova PD, Duplyakov DV. Circadian rhythms of cardiac troponins: mechanisms and clinical significance. Russian Journal of Cardiology 2020; 25(3S): 4061 https://doi.org/10.15829/1560-4071-2020-4061.

\section{Authors:}

Aleksey M. Chaulin - MD, Postgraduate student, Instructor, Department of Cardiology and Cardiovascular Surgery, Samara State Medical University, Samara, Russia; Physician, Samara Regional Clinical Cardiological Dispensary, Samara, Russia. https://orcid.org/0000-0002-2712-0227.

Julia V. Grigorieva - MD, PhD, Associate professor, Department of Histology and Embryology, Samara State Medical University, Samara, Russia. http://orcid.org/0000-0002-7228-1003.

Galina N. Suvorova - MD, DSc, Professor, Department of Histology and Embryology, Samara State Medical University, Samara, Russia. https://orcid.org/0000-0002-0462-1344.

Dmitry V. Duplyakov - MD, DSc, Professor, Department of Cardiology and Cardiovascular Surgery, Samara State Medical University, Samara, Russia; Deputy Medical Director, Samara Regional Clinical Cardiological Dispensary, Samara, Russia. https://orcid.org/0000-0002-6453-2976. 